\title{
A expansão do agronegócio no Brasil: as velhas práticas versus as novas práticas nas temporalidades geográficas
}

\section{The expansion of agribusiness in Brazil: the old practices versus the new practices in geographical temporalities}

Alberto Pereira Lopes - Doutor em Ciências (Geografia Humana) pela Universidade de São Paulo (USP). Professor da Universidade Federal do Tocantins (UFT). E-mail: beto@uft. edu.br

\section{Resumo}

É resultado de reflexões nos fóruns geográficos, nas nossas pesquisas de campo em relação à expansão de uma agricultura pautada no agronegócio brasileiro, que tem expropriado camponeses de suas pequenas propriedades, gerando conflitos e despejo. $\mathrm{O}$ objetivo é explanar sobre a estrutura fundiária no Brasil constituída pela desigualdade social e econômica, gerada pela concentração de terra e pela exploração advinda, nos dias atuais, do agronegócio, um modelo de desenvolvimento agroexportador de grande escala de produtividade. A metodologia baseia-se em autores que discutem essa temática conforme referências apontadas, além de trabalho de campo na região norte do estado do Tocantins, onde a expansão da monocultura da soja tem sido bastante propulsora. Este aspecto demonstra que o Estado não contribuiu para uma perspectiva renovadora no que diz respeito à reforma da estrutura fundiária. Pelo contrário, o Estado se configura como instrumento decisivo de coordenação e ação de todas as formas econômicas, contribuindo para a solidificação da classe dominante.

\begin{abstract}
This work is the result of reflections in the geographical forums, in our field research in relation to the expansion of a Brazilian agricultural agribusiness, which has expropriated peasants from their small properties, generating conflicts and eviction. The objective is to explain the land structure in Brazil constituted by social and economic inequality, generated by the concentration of land and by the current agricultural exploitation of agribusiness, a model of agroexport development of large scale of productivity. The methodology is based on authors who discuss this theme according to the aforementioned references, in addition to field work in the northern region of the State of Tocantins, where the expansion of soybean monoculture has been quite propulsive. This aspect shows that the State has not contributed to a renewing perspective regarding the reform of the land structure. On the contrary, the state is a decisive instrument of coordination and action of all economic forms, contributing to the solidification of the ruling class.
\end{abstract}

\section{Palavras-chave}

Agronegócio. Concentração. Trabalhador. Estrutura Fundiária.

\section{Keywords}

Agribusiness. Concentration. Worker. Land Ownership Structure. 


\section{INTRODUÇÃO}

A estrutura agrária brasileira, em toda a sua história, tem se constituído na centralização da terra nas mãos de poucos: os latifundiários. Estes têm expandido seus domínios, em todo território nacional, graças, sobretudo às políticas territoriais do Brasil a partir de 1850, na perspectiva de manter o domínio da grande propriedade advindo do regime de sesmarias que houvera sido suspenso em 1822. A Lei de Terras se constituiu um novo regime fundiário baseado no monopólio do Estado, criando dificuldades de novas posses a não ser por meio da compra.

A partir da criação da Lei de Terras em 1850 aqueles que não tiveram acesso, como, no caso, os camponeses, ficavam sujeitos a adquirir a terra por meio de seus trabalhos nas fazendas e acumular dinheiro a fim de comprar uma pequena parcela, conforme afirma Martins (1995, p. 42):

mediante o trabalho árduo os trabalhadores livres poderiam acumular e, em conseqüência, transformar-se em pequenos proprietários de terra. $\mathrm{O}$ acesso à terra se daria mediante a oferta compulsória de trabalho ao grande fazendeiro. Com essa mudança, a questão do campesinato é colocada em novos termos. Em primeiro lugar, porque liberta o camponês da grande propriedade, ao mesmo tempo que o subjuga a ela.

É diante dessas condições que todo projeto de desenvolvimento do país foi construído para servir a uma classe que crescia e se consolidava como burguesia nacional. Do século XVI ao século XVIII, é o momento de organização da classe dominante, pautada no trabalho de incorporação do indígena, do escravo, do afluxo migratório. O sistema escravista colonial é um exemplo de estruturação das sociedades coloniais, cuja riqueza era produzida por uma mão-de-obra sem custos: o escravo, que, ao mesmo tempo, representava um valor monetário.

Essa disponibilidade da força de trabalho fez com que a concentração da terra fosse cada vez mais um elemento essencial para acumulação da riqueza de uma ínfima classe, mas que tinha uma representação significativa no contexto da economia, já que a maioria da população, especialmente a rural, constituía a força motriz da burguesia.

O objetivo deste trabalho é explanar alguns pontos importantes sobre a estrutura fundiária no Brasil constituída pela desigualdade social e econômica, gerada pela concentração de terra, e pela exploração advinda nos dias atuais do agronegócio, um modelo de desenvolvimento agroexportador e de produtividade, em que seus conjuntos de relações praticam a superexploração do trabalho, peonagens, e trabalho escravo contemporâneo. 
As velhas práticas continuam com esta nova roupagem nos dias atuais, a do empreendimento com alto padrão tecnológico, que se processa na valorização de uma mão-de-obra qualificada para a consolidação do processo produtivo e para a acumulação do capital, constituído pela sua expansão territorial, expropriando as camadas mais vulneráveis no campo, que são as comunidades tradicionais (posseiros, pequenos trabalhadores, extrativistas, quebradeiras de coco, caiçaras etc.) que vivem de um processo produtivo de subsistência. É nesse sentido que iremos refletir sobre as velhas práticas de um país pautado na casa grande e na senzala e que perdura nos dias atuais com a precarização do trabalho e a chamada peonagem.

\section{A CONCENTRAÇÃO FUNDIÁRIA E A EXPLORAÇÃO DO TRABALHADOR}

A concentração de terras nas mãos de uma minoria vem causar a expansão da pobreza e da miséria, como também a expropriação dos camponeses graças ao desenvolvimento tecnológico no campo baseado na produção de monoculturas em grandes escalas, como soja, milho, cana-de-açúcar, para servir, sobretudo ao mercado externo e não o nacional. Esse processo demonstra que a estrutura fundiária no Brasil, por mais que tenha desenvolvido sua produção e sua produtividade com o advento do agronegócio, tem gerado exclusão, degradação ambiental e tantas outras barbáries.

Nessa perspectiva, o passado retrata o presente nas amarras da violência, da intolerância contra os direitos humanos, que continuam na sociedade brasileira e em sociedades semelhantes. Todo esse aspecto da estrutura agrária no Brasil revela os velhos quadros da colônia, como se o tempo em determinado momento não se modificasse no espaço geográfico, como a forma de utilização da terra e a organização agrária que daí resulta. Nas palavras de Fernandes, em relação à questão agrária, tal configuração é assumida:

Todavia, a questão estrutural permanece. Do trabalho escravo à colheitadeira controlada por satélite, o processo de exploração e dominação está presente, a concentração da propriedade da terra se intensifica e a destruição do campesinato aumenta. [...] A agricultura capitalista ou agricultura patronal ou agricultura empresarial ou agronegócio, qualquer que seja o eufemismo utilizado, não pode esconder o que está na sua raiz, na sua lógica: a concentração e a exploração (FERNANDES, 2005, p. 35).

A condição de exploração da força da mão-de-obra do pequeno trabalhador resultou em uma condição alienadora, no interior da qual este não tem condições 
de resistência contra a classe dominante, haja vista a sujeição que lhe é imposta. O trabalhador não se vê na produção da riqueza. É nesse sentido que, com a abolição da escravatura, o imigrante europeu que veio trabalhar principalmente nas lavouras de café não se constituiu como classe que viesse resistir e lutar contra a expansão do latifúndio, como afirma Caio Prado Júnior:

A massa escrava, mais tarde, apenas recém-egressa da escravidão, bem como os imigrantes que a partir do século passado vieram reforçar os contingentes de trabalhadores do campo brasileiro, nunca estiveram em condições de seriamente disputar para si o patrimônio fundiário da nação. Desde o início da ocupação e colonização do território brasileiro, e até hoje ainda, os títulos de propriedade e o domínio da terra galopam muito adiante da frente pioneira de penetração e ocupação (PRADO JÚNIOR, 1981, p. 25).

A classe camponesa organizada vem se constituir já no século XX com as ligas camponesas. Antes disso, iremos ter lutas populares, ou seja, conflitualidades no campo brasileiro, como por exemplo, a luta dos indígenas, do negro, as lutas messiânicas, o cangaço nordestino etc. São lutas importantes para a formação camponesa no Brasil, das quais resulta a reforma agrária como prioridade, abrindo o caminho para a transformação da sociedade.

De um lado, podemos perceber a luta dos camponeses que estavam à margem da sociedade, os sem terra, apenas com a esperança de um local para trabalhar, por outro, percebemos que a transformação acontece a partir da modernização da agricultura, pautada na dominação e exploração da mão-deobra, imobilizando o camponês de seus direitos. Se a agricultura modernizadora/ conservadora/patronal consegue um ápice em relação à produção e à produtividade, também é responsável pelos assassinatos e pelos conflitos, além do aliciamento das pessoas a condições análogas a de escravos, tal qual enfatiza Esterci:

a prática da imobilização da força de trabalho permitia aos empregadores: usurpar aos trabalhadores seus direitos, a força de suas organizações e a sua identidade de assalariados; baixar o custo da mão-de-obra; obter lucros fáceis e imediatos apropriando-se de recursos públicos em terras, obras, créditos e incentivos (ESTERCI, 1994, p. 85).

A partir da década de 1960 é que o Estado brasileiro criou leis jurídicas, regulamentando os direitos dos trabalhadores, fornecendo novos instrumentos legais diante das reivindicações. Assim, foi criado, em 1963, o Estatuto do Trabalhador, definindo os direitos trabalhistas no campo. Em 1964, o governo militar sancionou o Estatuto da Terra, traçando as linhas da política agrícola 
brasileira, e foi, nesse mesmo ano, criada a Confederação Nacional dos Trabalhadores na Agricultura (CONTAG).

Nesse cenário em que o Brasil formulava suas leis, as lutas, os conflitos, as mortes são características de um processo constante de contradições e desigualdades que são peculiares ao sistema instaurado, a do golpe militar de 1964. No entanto, a CONTAG e o Estatuto da Terra foram criados no meio da turbulência da violência instaurada contra os camponeses. É o que nos informa Oliveira (1997, p. 13), ao enfatizar que:

A violência do golpe militar de 64 sufocou o anseio de liberdade do morador sujeito dos latifúndios armados do Nordeste brasileiro. Caçaram e cassaram as lideranças dos camponeses em luta. Muitos 'fugiram' fingindo, sumiram, foram assassinados. Mas mesmo assim a CONTAG Confederação dos Trabalhadores da Agricultura - nasceu e não morreu.

A criação do Estatuto da Terra foi uma ferramenta silenciar as organizações camponesas. Dessa maneira, “o Estatuto da Terra era uma espécie de bandeira militar levada ao campo em luta para, através da guerra, impor a 'paz na terra'. Mais de 20 anos se foram e os militares não permitiram sequer que o Estatuto se tornasse Plano" (OLIVEIRA, 1997, p. 13).

No entanto, o Estatuto não saiu do papel, isso diante da realidade que se configurava no país, alianças reacionárias, latifundiários e representantes da União Democrática Ruralista (UDR) que estavam contra a reforma do campo para manter seus poderes de domínio. $O$ fosso estava instaurado contra os que defendiam a reforma agrária, e se transformava nos conflitos e nas mortes contra os camponeses, líderes sindicais, padres, pastores, agentes pastorais e advogados. Da mesma maneira, seguimos neste século as barbáries no campo contra os trabalhadores desprovidos de direitos, apenas deveres para cumprir na sua sina de criar a riqueza para o outro.

A violência no campo brasileiro, entre os sujeitos da luta pela terra, os camponeses, contra os dominadores latifundiários, torna-se cada vez mais evidente, no sentido da luta contra a expropriação. É por meio da busca de liberdade, da busca de sobrevivência, que o camponês tem migrado para lugares distantes para vender sua força de trabalho. A migração que atravessa temporalidades históricas tem levado este trabalhador à situação cativa, e nela (re) floresce o trabalho escravo. Esse problema que tem afetado a sociedade brasileira é resultado de fatores políticos, sociais e econômicos, mediante a concentração da riqueza que resulta no aspecto da pobreza e da miséria.

Toda a história da questão agrária brasileira está baseada nos conflitos, na expropriação do camponês, do trabalhador, do indígena e na sua sujeição 
para servir ao latifundiário que determina os limites de atuação da mão-de-obra, demonstrando a dominação como forma de força, que explora e que escraviza.

A concentração da terra é um dos fatores relevantes no uso repressivo da força de trabalho contemporâneo, diante do caráter da dívida que o trabalhador adquire quando vai prestar serviço ao dono da terra. Esse caráter da dívida e da repressão representa o grau de desigualdade que obriga as pessoas a se submeterem a situações que muitas vezes fogem do seu controle, devido a sua própria necessidade da luta pela sobrevivência. Nesse sentido, como afirma Esterci: "o caráter da dívida que escraviza, porque a desigualdade obriga as pessoas a se endividarem com outras, seja por não disporem de terras para trabalhar ou de recursos financeiros para adquirir a vista bens e serviços de quem necessitam" (ESTERCI, 1994, p. 43).

Tabela 1 - INCRA - Síntese da estrutura fundiária do Brasil - 2003

\begin{tabular}{l|l|r|r|r|r|r}
\hline \multicolumn{2}{c|}{ Grupos de área total } & $\begin{array}{c}\text { No de } \\
\text { imóveis }\end{array}$ & \multicolumn{1}{c|}{$\%$} & Área em ha & $\%$ & \multicolumn{1}{|c}{$\begin{array}{c}\text { Área } \\
\text { média (ha) }\end{array}$} \\
\hline Pequeno & Menos de 200 ha & 3.895 .968 & 91.9 & 122.948 .252 & 29.2 & 31.6 \\
\hline Médio & 200 a menos de 2000 ha & 310.158 & 7.3 & 164.765 .509 & 39.2 & 531.2 \\
\hline Grande & 2.000 ha e mais & 32.264 & 0.8 & 132.631 .509 & 31.6 & 4.110 .8 \\
\hline Total & & 4.238 .421 & 100,0 & 420.345 .382 & 100,0 & 99,2 \\
\hline
\end{tabular}

Fonte: INCRA - Org. OLIVEIRA, A. U.

Os dados da concentração de terra no Brasil demonstram o quanto a estrutura fundiária é desigual, o que acarreta na produção e reprodução da pobreza no país. Se observarmos os números da Tabela 1 , fica evidente o quanto a grande propriedade tem se expandido, de 2000 ha a mais de 5000 ha, chegando, segundo os dados, a 31,6\% em termos de área em hectares, enquanto a pequena propriedade com menos de 200 ha chega apenas a 29,2\%, conforme a Tabela 1. É preciso observar o número de imóveis distribuídos por número de área, cuja grande propriedade representa apenas 32.264 imóveis, enquanto que a pequena propriedade vem representar 3.895.968 imóveis.

Esta é uma realidade presente na atualidade diante da capacidade de expansão da propriedade, criando as condições necessárias para a territorialização do capital com o advento do agronegócio que se destina à grande produção baseada na tecnificação e mecanização no campo, para o influxo da valorização das commodities. Nesse cenário, a expansão de monoculturas no Brasil (soja, milho, cana-de-açúcar, eucalipto, pecuária de corte etc.) tem se constituído como necessária para os seus empreendedores a fim de especular a terra, criando condições de grilagens e dificuldades para a permanência das comunidades 
tradicionais no campo, com suas estruturas produtivas destinadas ao consumo e ao mercado interno, como os agricultores familiares.

\section{$2 O$ AGRONEGÓCIO: AS VELHAS PRÁTICAS NAS NOVAS PRÁTICAS PARA A EXPANSÃO DO CAPITAL}

Com a expansão do "novo negócio", ou seja, com o agronegócio, o resultado é a exclusão social, inter-relacionada com o processo de desigualdade e de pobreza. O que se percebe é que a exclusão é uma categoria que traz consigo o aprofundamento das desigualdades sociais, econômicas e políticas. No campo, diante da exclusão imposta pela expansão do agronegócio, as comunidades que vivem de maneira simples, baseada numa agricultura rudimentar destinada ao consumo e ao pequeno excedente, vivem dilemas que se relacionam com a pobreza e com a expulsão de suas terras.

Percebe-se que a exclusão está relacionada a uma determinação imposta pelos donos dos capitais, em que se concentra a riqueza e se estabelecem critérios de trabalho. A exclusão gera a incapacidade do homem, enquanto sujeito social, de viabilizar a sua vida social, diante do nível de distribuição de recursos que gera a desigualdade.

Nestes termos, a única forma de fazer com que o homem se torne incluso nesse processo é a capacitação funcional. E para isso é necessário se capacitar em cursos técnicos para assumir as frentes de trabalho nas grandes propriedades.

Nesse sentido, estamos nos deparando com uma visão estruturalista em que o Estado tem o dever de incluir o cidadão em frentes compensatórias para a sua vida social. No caso do campo, teremos a distribuição de terras em projetos de colonização criados pelo Estado para os camponeses. No entanto, as ações individuais são necessárias para incluí-los na sociedade, como a participação nas instituições de ensino, a competição de trabalhos, a qualificação etc. Estas viabilizações, tidas como individuais, requerem o acesso do homem aos serviços necessários, para que seja competitiva a sua força de trabalho para o mercado. Nessa perspectiva, Singer (2000, p. 60) destaca o discurso com o qual temos nos deparado a respeito da desigualdade:

Os estruturalistas enxergam a desigualdade como uma decorrência natural da economia de mercado, que precisa ser contrabalançada por mecanismos que redistribuam a renda, direta ou indiretamente, dos ricos aos pobres. Os individualistas atribuem a maior parte da desigualdade às tentativas bem-intencionadas, contudo contraproducentes, de resolvê-la por meios institucionais. Eles vislumbram a origem da desigualdade nas naturais e inevitáveis diferenças entre os indivíduos. 
Nestes termos, essas categorias são integradoras, ou seja, uma não exclui a outra diante da própria condição de desigualdade e contradição que o sistema capitalista apresenta, em sua forma articulada na dinâmica da acumulação do capital. Para compreendermos essa relação de desigualdade social, econômica, pontuamos as considerações do professor Ariovaldo Umbelino de Oliveira, que entende esse processo de desigualdade e contradição dentro do sistema capitalista, assim justificando:

O que isso significa? Significa que, para entendermos a distribuição social e/ ou territorial das desigualdades e contradições do desenvolvimento capitalista, devemos compreender que elas estão ligadas aos processos históricos específicos de cada país ou nação. Ou seja, cada formação econômico-social concreta revela no seu interior esse processo desigual e contraditório espacial e temporalmente (OLIVEIRA, 1994, p. 49).

Essa contradição encontra-se nas relações de trabalho entre capitalistas/ fazendeiros/capitalistas com o trabalhador, cuja única forma de sobreviver é a sua mão-de-obra que está disponível para os donos dos meios de produção. Dessa maneira, as relações capitalistas criam outras formas de relações pautadas na acumulação primitiva do capital, em que o trabalhador é obrigado a se alienar nas formas de trabalho que serão oferecidas pelos capitalistas por não ter outro meio de sobrevivência. A este respeito podemos exemplificar o sistema de peonagem nas fazendas de produção de commodities, como soja, carvão, milho e cana-de-açúcar em que o camponês é submetido a um trabalho exaustivo e sem direitos trabalhistas.

Trata-se de uma relação não capitalista de produção, cuja ausência do assalariamento é essencial para produção e reprodução do capital. O camponês é subordinado, e o seu ganho é disfarçado de salário. É a forma mais exorbitante de exploração do trabalho alheio. Relativo a esse processo, Martins (1998, p. 21) afirma que:

A produção capitalista de relações não capitalistas de produção expressa não apenas uma forma de reprodução ampliada do capital, mas também a reprodução ampliada das contradições do capitalismo - o movimento contraditório não só de subordinação de relações pré-capitalistas, mas também de criação de relações antagônicas e subordinadas não-capitalistas. Nesse caso, o capitalismo cria a um só tempo as condições da sua expansão, pela incorporação de áreas e populações às relações comerciais, e os empecilhos à sua expansão, pela não mercantilização de todos os fatores envolvidos, ausente o trabalho caracteristicamente assalariado.

Portanto, as velhas práticas tornam-se maculadas diante da nova prática do chamado agronegócio baseado no processo produtivo em alta escala para o

Novos Cadernos NAEA • v. 20 n. $1 \bullet$ p. 95-109 • jan-abr 2017 
mercado capitalista global, com sua expansão contraditória e desigual de relações não capitalistas de produção para acumulação do capital. Essa nova modalidade chamada de agricultura moderna tem, em seu caráter, a exploração da mais valia, sobretudo social, como também a produção de mercadorias para o mercado externo.

Nesses termos, o agronegócio surge com uma nova abordagem de defesa do processo produtivo e expansão da terra para a solução do abastecimento de alimentos, seja para o mercado interno, seja para o mercado externo, eliminando assim a fome e a pobreza. Essa é a visão dos seus defensores, que buscam nos transgênicos a solução para matar a fome dos que não têm acesso à alimentação. Nessa visão, assim se posicionam os defensores dos transgênicos: “o discurso empresarial a favor dos transgênicos lança mão do suposto de que se posicionar contra significa um atraso em face da ciência e do avanço tecnológico. Os transgênicos representariam o progresso" (BRUNO, 2008, p. 87).

Para os movimentos sociais, os transgênicos vão representar o outro lado da moeda: o aumento da desigualdade social e da pobreza. Na verdade, o que está por trás da grande produção e da produtividade é o aumento do faturamento das multinacionais, além do estabelecimento do monopólio das sementes, dificultando a democratização e a soberania alimentar dos povos.

Para as reflexões do Movimento Sem Terra (MST) a respeito dos transgênicos, Bruno enfatiza que:

Segundo suas lideranças, a luta do Movimento é fundamentalmente uma luta pela preservação da natureza e da vida - uma vida com dignidade, afirmam. E acrítica aos transgênicos é parte de uma luta política maior: pela terra e a reforma agrária; pela garantia de acesso à habitação, infraestrutura, créditos, assistência técnica, condições de comercialização de produção, educação, saúde (BRUNO, 2008, p. 91).

O agronegócio estabelece no seu discurso uma relação de poder e dominação diante da sua capacidade produtiva, constrói o seu discurso baseado nos dados da balança comercial brasileira e esquece os dilemas que são resultados de sua expansão no território nacional. Em contra-argumentação, os movimentos sociais têm uma posição bastante significativa, como afirma Bruno (2008, p. 91):

o argumento dos sem-terra é de que a fome, [sic] não é uma questão de falta de alimentos e sim um problema relacionado à pobreza e ao não acesso aos recursos produtivos. Em resposta no argumento sobre o aumento da produtividade, vemos a idéia denúncia de que os transgênicos aumentam, sim, o faturamento das multinacionais e impõe risco de contaminação geral a todos os cultivos e destruição da biodiversidade, expressa como desigualdade social. Contra o monopólio de sementes por 
empresas transnacionais, a defesa das sementes como patrimônio dos povos a serviço da comunidade: pela reprodução e acesso democrático ao uso das sementes, reivindicam.

A valorização da terra, para as comunidades tradicionais, camponeses é um dos aspectos importantes para a permanência da biodiversidade do planeta, para se produzir sem que haja a degradação ambiental. A técnica não poderá ser um recurso para satisfazer a expansão sem limite do agronegócio, devastando a terra enquanto bem de vida, para satisfazer ao mercado internacional de produtos primários.

Campos Lindos (TO) é um dos municípios com maior índice de produção para o agronegócio, sobretudo a soja, mas também apresenta um dos menores Índices de Desenvolvimento Humano (IDH) do Brasil, com 0,544, segundo os dados de 2010 do Instituto Brasileiro de Geografia e Estatística (IBGE). O que isto apresenta? Pobreza, miséria, uma população que fica à margem da sociedade, vulnerável ao trabalho escravo.

É necessário repensar o que significam as novas tecnologias no campo, enquanto recurso para melhoria da capacidade de produção da classe trabalhadora sem agredir o meio ambiente, preservando-o para gerações futuras. Nessa perspectiva, o agronegócio é a nova modalidade com eficiência em termos produtivos e tecnológicos diferente dos velhos modelos do latifúndio, mas se assemelham, nas relações sociais na exploração do camponês, a uma relação de acumulação primitiva do capital com relações não capitalistas de produção como afirma Martins (1998).

Em relação à expansão do agronegócio nas regiões de fronteiras agrícolas, como na Amazônia, onde o desmatamento tem sido significativo para a territorialização do capital, Paulino (2015, p. 11) aponta como o pacto entre os interessados e os responsáveis pelo agronegócio opera para ocultar o índice de desmatamento:

A capacidade que tem o pacto político-midiático-oligárquico de informação para ocultar faz com que tais números, em vez de serem coletivamente compreendidos em correspondência à sua significância territorial e aos impactos reais, favorecessem os argumentos dos ruralistas de que a incorporação dos princípios de sustentabilidade e responsabilidade ambiental, do que denominam agronegócio, já estaria produzindo resultados, a exemplo destes mencionados. A própria eliminação do conceito de latifúndio em favor dessa nomenclatura é parte dessa roupagem moderna forjada no plano das representações, sem correspondente lastro na realidade. 
A relação entre o agronegócio e o latifúndio se caracteriza pelas relações contraditórias e desiguais do capital, isso diante da própria acumulação primitiva que é utilizada como forma concebível de lucro no processo produtivo. A tecnologia é um elemento importante no processo da informação e eficiência econômica no campo para o agronegócio. É na demonstração da eficiência que o agronegócio se sustenta, na simbologia da produção e da produtividade é que estão os discursos soberanos de seus defensores, como se delineia nesta afirmação de Prado Júnior (1981, p. 27) em relação à tecnologia no campo:

A elevação do nível tecnológico das atividades rurais parece reunir todos os fios da meada, e construir a maneira de atender a todos os interesses em jogo [...] Mas ainda aí é preciso distinguir, porque, de um lado, a avaliação de uma técnica não se pode fazer em temos absolutos, sem consideração a outras circunstâncias que a fazem ou não recomendável em dada situação. A técnica é um meio, e não um fim em si própria; e por isso somente vale função do fim a que se destina e dos problemas concretos que com ela se objetiva resolver. Doutro lado, o progresso tecnológico não significa necessariamente uma melhoria de condições do trabalhador. E, às vezes até pelo contrário, pode agravá-las.

Esta eficiência econômica também estava relacionada com a política mediante seus representantes no Congresso Nacional e no próprio governo Dilma com a senadora Kátia Abreu, representante da Confederação Nacional da Agricultura e Pecuária (CNA), com o discurso de mais investimentos para agricultura patronal e maior abertura nas frentes de expansão da grande propriedade para o processo produtivo agroexportador. Estamos diante de dilemas políticos. De um lado, os donos do capital que clamam por mais investimentos para o processo produtivo, e, de outro, os que clamam por justiça para permanecer no campo, os camponeses que são vitimados pelos conflitos instaurados pela expansão territorial do capital.

Nesse sentido, a prática que o agronegócio tem utilizado de forma nefasta é valorizar a grande propriedade, excluir os camponeses, criar a desigualdade e com isso a conflitualidade gerada pela miséria e a fome dos que trabalham não para si, mas para o enriquecimento muitas vezes ilícito do outro. Não obstante, poderemos analisar que a pobreza não poderá ser algo natural, mas produzida pela concentração dos recursos da natureza que estão sob controle de grupos poderosos, como os representantes da grande propriedade patronal.

O discurso dos representantes do agronegócio sobre a pobreza, a miséria, bem como sobre as relações sociais e culturais dos trabalhadores, não é diferente daquilo que sempre pregaram no decorrer da história. A preocupação e a defesa de tais questões presentes na preleção na prática é contraditória, relacionada aos 
seus interesses e aos resultados da acumulação da riqueza, e não nos milhares de pessoas vivendo em situações degradantes.

É um discurso contraditório, cuja relação de poder e de dominação que o engendram se incorporam às pretensões da acumulação primitiva do capital por meio da força do trabalhador, e este por sua vez torna-se obrigado a prestar o serviço ao capital. Os seus direitos de trabalhador não eram de fato garantidos perante a lei. Pelo contrário, tornam-se vulneráveis às mediações do patrão que lhe estabelece as regras e os critérios das relações não capitalistas, ou seja, do trabalho que não é pago à força de trabalho prestada.

Portanto, o discurso dos donos dos meios de produção, sobre a solidariedade e sobre a defesa da melhoria da qualidade de vida, torna-se maculado diante do crescimento da pobreza e da exclusão dos trabalhadores em relação ao acesso à terra. Sem esquecer as comunidades tradicionais que são afetadas no território construído dezenas ou centenas de anos e que estão sendo dizimados pela expansão do agronegócio. Dizemos isso pois, de acordo com Bruno (2008, p. 93):

Se, de um lado, o discurso patronal sobre a responsabilidade social e pelo fim da pobreza ganha maior visibilidade e se constitui em preocupação, de outro, não se observa em contrapartida uma mudança significativa na natureza das relações de trabalho: a intensificação do trabalho, em especial nas regiões canavieiras, e o recurso do trabalho escravo nas frentes de expansão são uma realidade e se constituem em campo de tensão e conflitividade.

A falta de distribuição de renda equitativa e de reforma agrária é fator que contribui para o estado de exclusão do trabalhador que busca, por meio da sua força de trabalho, a sua existência como categoria que em determinado espaço se organiza e resiste à exploração, quando outros são submetidos à dominação do latifundiário. Como categoria de trabalhadores organizados, por um lado, iremos encontrar os que fazem parte de entidades, sindicatos e movimentos de resistências. Por outro lado, iremos encontrar os desprovidos de organização, como os boias-frias, os posseiros e os aliciados para o trabalho escravo. Essas categorias são dominadas pelos donos de capital que compram a sua força de trabalho como uma mercadoria especial que irá gerar valores, para expandir os seus meios de produção.

Todo o processo de expansão da grande propriedade no Brasil tem sido constituído de muitos conflitos, de disputas entre o que tem o capital e o que sobrevive da subsistência da sua força do trabalho. É uma luta de desiguais, em que existe o dominador e o dominado. O dominador expropria e exclui, e o outro 
ocupa a terra e se ressocializa, e constrói novas formas de lutas para permanecer como camponês. Este retrato da questão agrária no Brasil, por mais que tenha um campo desenvolvido e mecanizado, é gerador da conflitualidade que gera a luta de classes, quando estas são organizadas. O conflito é resultado do desenvolvimento da agricultura mecanizada, de cujo processo o camponês é excluído, o que gera desemprego e incertezas de um futuro promissor (FERNANDES, 2005).

Quando falamos da agricultura mecanizada, é porque esta tem tido um papel importante no contexto da exclusão do camponês. É a agricultura patronal que representa a grande propriedade, porque seu produto é produzido principalmente para o mercado externo. Da mesma maneira, a pecuária tem um papel de extrema importância na economia brasileira, mas é a principal responsável pela servidão e pelos diferentes níveis de subordinação do trabalhador.

\section{CONSIDERAÇÕES FINAIS}

A realidade que se descreve e que se discute neste trabalho mostra como as velhas práticas pautadas no latifúndio são semelhantes às novas práticas criadas pelo agronegócio, estratégia que transforma a agricultura em negócio rentável ao mercado mundial regulado pelo lucro com o discurso de produção para a humanidade. Observamos esse discurso fantasioso porque a produção de alimentos gerada pelo agronegócio tem sido para satisfazer a hegemonia de grupos multinacionais no contexto neoliberal para acumulação capitalista, criando riquezas para uma pequena parcela e intensificando o grau de pobreza e miséria, graças à sua expansão territorial.

Nesse sentido, procuramos analisar a estrutura fundiária no Brasil, para compreender os conflitos diante de sua concentração, que se constitui como elemento primordial para a reprodução capitalista de produção. Fica clara essa interface dos donos dos meios de produção, sobretudo na agricultura, com o advento do agronegócio, pois territorializa e expropria os camponeses e comunidades tradicionais promovendo o desenvolvimento e o conflito.

A expansão do "novo negócio", ou o agronegócio, tem como resultado a produtividade em grande escala, acompanhada da exclusão social inter-relacionada com o processo de desigualdade e de pobreza. O que se percebe é que a exclusão é uma categoria que traz consigo o aprofundamento das desigualdades sociais, econômicas e políticas. No campo, diante da exclusão imposta pela expansão do agronegócio, as comunidades que vivem de maneira simples, baseada numa agricultura de subsistência destinada ao consumo e ao pequeno excedente, vivem dilemas que se relacionam com a expropriação de suas terras e a violência. 
Esses dilemas dos camponeses são notórios, quando presenciamos, na gleba Tauá na região do Bico do Papagaio do estado do Tocantins, a expansão da grande propriedade nas terras dos posseiros, que alegam lhes pertencer, quando na verdade são verdadeiros grileiros, que impõem seu poder de mando para expandir seus negócios nas terras devolutas do Estado. Apresentam documentos falsos para que os camponeses desocupem e ou, caso haja resistência, são despejados, tendo as casas e as plantações queimadas. Famílias são desterradas sem direito a nada do fruto de seu trabalho, as quais durante anos se estabeleceram no lugar e criaram laços de integridade.

Diante dessas considerações, podemos afirmar que o agronegócio se apropria de espaços que atendem os seus interesses, e não os interesses dos lugares. Essa afirmação é pertinente quando se observa a cidade de Campos Lindos (TO), cujo IDH é um dos mais baixos do Brasil, enquanto que o município é um dos maiores produtores de soja.

Portanto, em termos de distribuição de renda, o agronegócio é nulo, seus promotores utilizam do seu poder de força econômica para viabilizar seus negócios. Estão colocando em curso novas práticas com articulações políticas sobretudo para se apropriarem de novos espaços para a territorialização do capital.

\section{REFERÊNCIAS}

BRUNO, R. Agronegócio e novos modos de conflitualidade. In: FERNANDES, B. M. Campesinato e agronegócio na América Latina: a questão agrária atual. São Paulo: Expressão Popular, 2008. p. 83-105.

ESTERCI, N. A dívida que escraviza. CPT (Comissão Pastoral da Terra). Trabalho escravo no Brasil contemporâneo. Goiânia: Edições Loyola, 1999. p. 101-125.

Escravos da desigualdade: um estudo sobre o uso repressivo da força de trabalho de hoje. Rio de Janeiro: CEDI; Koinonia, 1994.

FERNANDES, B. M. Questão agrária: conflitualidade e desenvolvimento territorial. In: BUAINAIN, A. M. (Ed.). Luta pela terra, reforma e gestão de conflitos no Brasil. Campinas-SP: Ed. UNICAMP, 2005. p. 173 - 230.

MARTINS, J. de S. O cativeiro da terra. 7. ed. São Paulo: HUCITEC, 1998. Fronteira a degradação do outro nos confins do humano. São Paulo: Hucitec, 1997. 
Os camponeses e a política no Brasil: as lutas sociais no campo e seu lugar no processo-político. 5. ed. Petrópolis-RJ: Vozes, 1995.

OLIVEIRA, A. U. de. A geografia das lutas no campo. 8. ed. rev. e amp. São Paulo: Contexto, 1997.

O campo brasileiro no final dos anos 80. In: STÉDILE, J. P. (Coord.). A questão agrária hoje. 2. ed. Porto Alegre: UFRGS, 1994. p. 45-67.

Integrar para (não) entregar: políticas públicas e Amazônia. Campinas-SP: Papirus, 1988.

Modo capitalista de produção e agricultura. 2. ed. São Paulo: Ática, 1987.

PAULINO, E. T. Questão agrária: lutas, conflitos territoriais e contradições sociais no mundo do século XXI. In: MITIDIERO JÚNIOR, M. A.; GARCIA, M. F.; VIANA, P. C. G. A questão agrária no século XXI: escalas, dinâmicas e conflitos territoriais. São Paulo: Outras Expressões, 2015. p. 9-24.

PRADO JUNIOR, C. A questão agrária no Brasil. 3. ed. São Paulo: Brasiliense, 1981.

SINGER, P. Globalização e desemprego: diagnóstico e alternativas. 4. ed. São Paulo: Contexto, 2000. 
